\title{
Contribution de l'enseignant d'anglais de spécialité à la conscientisation des stratégies d'apprentissage
}

Jacqueline Percebois

\section{OpenEdition}

\section{Journals}

Édition électronique

URL : http://journals.openedition.org/asp/1470

DOI : $10.4000 /$ asp. 1470

ISBN : 978-2-8218-0390-9

ISSN : 2108-6354

\section{Éditeur}

Groupe d'étude et de recherche en anglais de spécialité

Édition imprimée

Date de publication : 30 décembre 2002

Pagination : 141-153

ISSN : 1246-8185

Référence électronique

Jacqueline Percebois, « Contribution de l'enseignant d'anglais de spécialité à la conscientisation des stratégies d'apprentissage », ASp [En ligne], 37-38 | 2002, mis en ligne le 21 juillet 2010, consulté le 01 mai 2019. URL : http://journals.openedition.org/asp/1470 ; DOI : 10.4000/asp.1470

Ce document a été généré automatiquement le 1 mai 2019.

Tous droits réservés 


\title{
Contribution de l'enseignant d'anglais de spécialité à la conscientisation des stratégies d'apprentissage
}

\author{
Jacqueline Percebois
}

\section{NOTE DE L'ÉDITEUR}

L'auteur de cette contribution n'a pas autorisé sa publication en ligne.

\section{RÉSUMÉS}

Cet article aborde la recherche dans le domaine des stratégies d'apprentissage des langues secondes. Il étudie en premier lieu diverses notions de conscience terminologique, philosophique (introspection, conscience, mémoire) et linguistique. Il considère ensuite les fondements théoriques des stratégies et styles d'apprentissage. Enfin, il analyse divers aspects du rôle de l'enseignant de langue, et plus spécifiquement, celui d'enseignant de L2 de spécialité.

This paper deals with research in the field of second language learning strategies. First it studies various notions of consciousness: terminological, philosophical (introspection, consciousness, memory) and linguistic notions. Then it examines theoretical bases of learning strategies and styles. Lastly, it analyses various aspects of the language teacher's role, and more precisely, the L2 ESP teacher's role. 
INDEX

Mots-clés : anglais de spécialité, conscientisation, efficacité, stratégie d'apprentissage, style d'apprentissage

Keywords : consciousness raising, efficiency, English for Specific Purposes, L2 learning strategy, learning style

\section{AUTEUR}

\section{JACQUELINE PERCEBOIS}

Jacqueline Percebois, maître de conférences HDR, enseigne l'anglais économique à la Faculté des Sciences économiques de l'Université Montpellier 1. Après L'Anglais de la Microéconomie et L'Anglais de la Macroéconomie, elle a publié, en septembre 2002, Terminologie Anglais/Français du Commerce International -Théories, Politiques, Accords et Institutions (Economica). Elle est membre de l'EA 2025 «Anglais de spécialité / Didactique de la langue » (Université Bordeaux 2). Ses principaux domaines de recherche sont la lexicologie comparée, l'analyse du discours en anglais économique et la didactique de l'anglais de spécialité. jacqueline.percebois@univ-provence.fr 